\title{
INVESTIGAÇÃO COM O PROBLEMA DO MAPA DO TESOURO
}

\author{
INVESTIGATION WITH THE TREASURY MAP
}

\author{
Gustavo Rosas Rodrigues ${ }^{1}$ \\ José Carlos Pinto Leivas² \\ Lidiane Buligon ${ }^{3}$
}

\begin{abstract}
RESUMO: Apresenta-se, neste artigo, uma pesquisa de cunho qualitativo, recorte de uma dissertação de mestrado do primeiro autor, a qual teve por objetivo analisar como estudantes do Ensino Médio realizam uma atividade investigativa na resolução do problema clássico, 'A Caça ao Tesouro', adaptado em uma situação real no Parque São Luiz, pertencente à escola. A pesquisa foi realizada durante o mestrado e o recorte aqui adaptado explorou como metodologia de ensino a Investigação Matemática. Os sujeitos foram 10 estudantes dos três níveis do Ensino Médio de uma escola privada no interior gaúcho, na qual o primeiro autor é professor e líder de um grupo específico criado para resolver problemas curiosos, os quais retomam e complementam temas do currículo do referido nível de ensino. Os resultados da pesquisa mostraram que os estudantes compreenderam o problema original adaptado às suas realidades, elaboraram estratégias de busca ao tesouro e o encontraram, atingindo o objetivo proposto. Conclui-se, além disso, que os fatos históricos trazidos pelo professor os motivaram a resolver o problema adaptado criativamente e com entusiasmo o que nem sempre ocorre em aulas convencionais. Dessa forma, a metodologia de Investigação Matemática mostrou-se eficiente para os sujeitos envolvidos na pesquisa.
\end{abstract}

PALAVRAS-CHAVE: Caça ao tesouro. Investigação matemática. Ensino médio. História da matemática.

\begin{abstract}
This article presents a qualitative research, part of a master's thesis by the first author, which aimed to analyze how high school students carry out an investigative activity in solving the classic problem, 'The Treasure Hunt', adapted in a real situation in Parque São Luiz, belonging to the school. The research was carried out during the master's degree and the clipping adapted here explored as a teaching methodology the Mathematical Investigation. The subjects were 10 students from three levels of high school from a private school in the interior of the state of Rio Grande do Sul, in which the first author is a teacher and leader of a specific group created to solve curious problems, which retake and complement curriculum themes at that level of teaching. The research results showed that the students understood the original problem adapted to their realities, elaborated treasure search strategies and found it, reaching the proposed objective. It is also concluded that the historical facts brought by the teacher motivated them to solve the problem creatively and enthusiastically adapted, which does not always occur in conventional classes. Thus, the Mathematical Investigation methodology proved to be efficient for the subjects involved in the research.
\end{abstract}

KEYWORDS: Treasure hunt. Mathematical research. High school. History of Mathematics.

\footnotetext{
1 Universidade Federal de Santa Maria. E-mail: gus_santacruz@yahoo.com.br

(1) https://orcid.org/0000-0003-0172-8389

2 Universidade Franciscana. E-mail: leivasjc@gmail.com

iD https://orcid.org/0000-0001-6876-1461

3 Universidade Federal de Santa Maria. E-mail: profbuligon@gmail.com

(iD) https://orcid.org/0000-0002-5907-3584

- Informações completas da obra no final do artigo
} 


\section{ENSIN@UFMS 2021}

ISSN 2525-7056

\section{Introdução}

Embora ainda perdure no cenário nacional referências de que há abandono no ensino de Geometria, muitas práticas e investigações estão surgindo a respeito, especialmente no que se refere à utilização da Geometria Dinâmica no enfrentamento de resolução de problemas tradicionais na Matemática dedutiva, em especial. A filosofia, tanto geral, quanto da Matemática, em sua forma dedutiva, particularmente, pode ser interpretada à luz dos tempos atuais para a Educação Matemática e softwares como o Cabri, o Geogebra, o Poly, dentre outros, tendem a favorecer a evolução do ensino desta área.

Lakatos (1978), um clássico, no livro A Lógica do Descobrimento Matemático Provas e Refutações não deixa de ser atual na medida em que o professor se volta a ele para desenvolver temas clássicos à luz de novas metodologias em complementação às tecnologias, como, na investigação matemática ou resolução de problemas. Ao tratar sobre os enfoques dedutivistas e heurísticos, o autor afirma: "A metodologia euclidiana desenvolveu certo estilo obrigatório de apresentação. Vou designá-lo de 'estilo dedutivista'. Esse estilo começa com uma lista laboriosamente feita de axiomas, lemas e/ou definições" (p. 185). Percebe-se, na referida citação, que essa forma de desenvolver Geometria, possa ser o que afasta os estudantes da descoberta no fazer geométrico.

Em relação ao estilo heurístico, o autor afirma que ele acentua, ao contrário do estilo dedutivista, o qual "[...] rompe as definições geradas pela prova dos antepassados, apresenta-as no vazio, de modo artificial e autoritário, ocultando os contraexemplos globais que conduziram a descobrimentos" (LAKATOS,1978, p. 188). O autor enfatiza a situação problema a partir da lógica que origina um novo conceito e isso é algo que se preconiza atualmente na questão do aluno ser o construtor do seu próprio conhecimento.

A Base Nacional Curricular Comum (BNCC) enfatiza para o ensino fundamental que "[..] a aproximação da Álgebra com a Geometria desde o início do estudo do plano cartesiano [...]" (BRASIL, 2017, p. 272). Indica, além disso, que Geometria não pode ser restringida a mera aplicação de fórmulas de áreas e volumes, por exemplo. Recomenda, ainda, que "os recursos didáticos, como malha quadriculada, ábacos, livros, vídeos, calculadoras, planilhas eletrônicas e softwares de geometria dinâmica, têm um papel essencial para a compreensão das noções matemáticas" (p. 276).

Relacionado às habilidades e competências para o ensino médio, destaca-se na BNCC: 
1. Utilizar estratégias, conceitos e procedimentos matemáticos para interpretar situações em diversos contextos, sejam atividades quotidianas, sejam fatos das Ciências da Natureza e Humanas, das questões socioeconômicas ou tecnológicas, divulgados por diferentes meios, de modo a contribuir para uma formação geral.

2. Utilizar estratégias, conceitos, definições e procedimentos matemáticos para interpretar, construir modelos e resolver problemas em diversos contextos, analisando a plausibilidade dos resultados e adequação das soluções propostas, a fim de construir argumentação consistente.

A partir desses pressupostos indicados por documentos oficiais, Rodrigues (2014) afirma que,

\begin{abstract}
com o passar dos anos, foram sendo criadas novas aplicações para o estudo da Geometria. Além disso, estudos sobre novas geometrias foram sendo desenvolvidos e, com isso, esse ramo da Matemática foi ganhando cada vez mais importância. No ensino superior, é relevante a ênfase que se dá ao estudo da Geometria. O próprio PROFMAT é um exemplo disso, pois oferece disciplinas que propiciam ao mestrando um aprofundamento nos quesitos tangentes à Geometria (p. 14).
\end{abstract}

Assim, justifica-se o presente artigo, que apresenta um recorte adaptativo da dissertação de mestrado do primeiro autor, que investigou de que forma um grupo de estudantes do ensino médio adaptou a resolução de um problema clássico para a atualidade com o uso da Geometria Dinâmica oferecida pelo software Geogebra. Neste artigo deixou-se de analisar as questões relativas à tecnologia e objetivou-se analisar como estudantes do ensino médio realizam uma atividade investigativa na resolução do problema clássico, 'A Caça ao Tesouro', adaptado em uma situação real no Parque São Luiz, pertencente à escola.

Na sequência, apresenta-se alguns pressupostos teóricos que nortearam a pesquisa de mestrado, com um recorte sobre Geometria e Geometria Analítica, temas abordados na pesquisa.

\title{
Revisitando a literatura
}

No histórico da Geometria encontra-se em Boyer (2010) informações de que as civilizações egípcia e babilônica deixaram para a humanidade documentos comprovando conhecimentos importantes para tal área, os quais se propagaram até os dias atuais. Um 


\section{ENSIN@UFMS 2021}

ISSN 2525-7056

trabalho conhecido é o de Hipócrates, ao se referir a Tales de Mileto como sendo aquele que introduziu Geometria na Grécia. Porém, outros como Arquimedes e Apolônio têm pouca citação na História da Matemática.

Ao analisar um texto histórico sobre o desenvolvimento da Geometria, os estudantes podem acompanhar o desenvolvimento do programa pelo professor, explorando as atividades que envolvem os seguintes conceitos geométricos: noções e proposições primitivas (ponto, reta, plano); segmento de reta; ponto médio; distância entre dois pontos; perpendicularidade; rotação e ângulos, dentre outros. Esses lhes permitirão desenvolver conteúdos geométricos mais avançados no transcorrer do ensino médio e superior. Assim, recorrer à construção histórica da Geometria é relevante na formação do indivíduo.

Voltando a Boyer (2010), consta que Pitágoras de Samos deu nome a um dos mais importantes teoremas sobre o triângulo retângulo. Com isso inaugurou-se um novo conceito para demonstrações em Matemática. Enquanto a escola pitagórica constituía uma espécie de seita filosófica, envolvendo em mistério seus conhecimentos, os "Elementos" de Euclides (Figura 1) representavam a introdução de um método consistente que contribui há mais de vinte séculos para o progresso das ciências.

Figura 1. Elementos de Euclides

Fonte: Eves (2004, p.172).

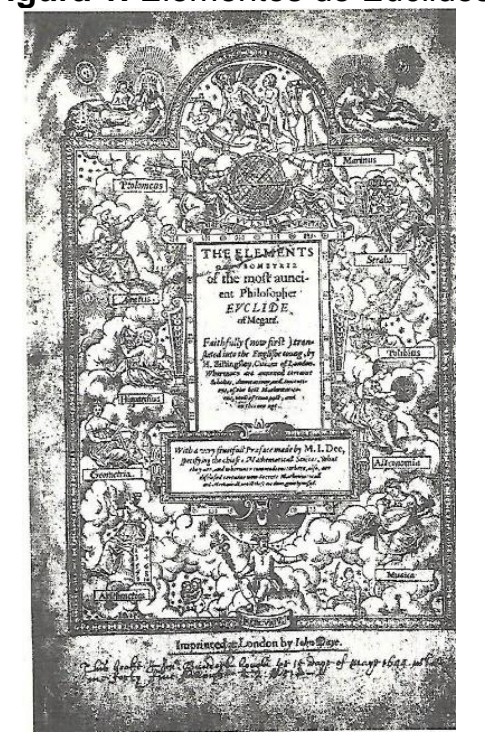

A respeito de ensaios sobre o modelo axiomático constantes dos Elementos, Reis (1996) diz que eles partem de conceitos e proposições, admitidos sem demonstração, denominadas postulados ou axiomas para a construção, de maneira lógica, de toda a obra. O autor afirma que, para isso, são necessários três conceitos fundamentais (o ponto, a reta 
e o círculo) e cinco postulados. Os postulados são os fundamentos para o estudo da Geometria Euclidiana. Não se pode ignorar a existência de geometrias não euclidianas, as quais surgiram, principalmente, dos questionamentos sobre o quinto desses postulados. Matemáticos tentaram demonstrar que não se tratava de um postulado e sim de um teorema. Nessas tentativas, uns o negavam, ou seja, não existir uma única paralela a uma reta dada passando por um ponto fora dela e outros, que existia mais de uma. Com isso, foram criadas as duas principais geometrias denominadas Não-Euclidianas: Elíptica e Hiperbólica.

A Geometria Analítica, ou Geometria das Coordenadas, seguiu a evolução histórica da Geometria, agregando ferramentas para a resolução de problemas geométricos, a saber, a conectando com a Álgebra. Reciprocamente, a Geometria Analítica fornece interpretações geométricas para questões algébricas. Tal conexão entre as duas áreas tornou-se ferramenta importante para o desenvolvimento da própria Matemática.

De acordo com Roque (2012), foram os gregos que deram à Geometria seu caráter de ciência dedutiva. No entanto, faltava, ainda, à Geometria grega o que viria a ocorrer com a Álgebra estabelecendo um princípio unificador de forma operacional. Os gregos não eram bons o suficiente em Álgebra sendo que somente no século XVII que ela estaria razoavelmente aparelhada para uma fusão criativa com a Geometria.

O fato da inexistência de condições para uma descoberta não elimina a genialidade de um estudioso para outras. A Geometria Analítica corresponde a isso, pois uma vez que é creditada a Pierre de Fermat (1601-1665) e René Descartes (1596-1650) a responsabilidade por esse avanço científico. Fermat e Descartes não trabalharam juntos: a Geometria Analítica é um dos muitos casos, em ciência, de descobertas simultâneas e independentes ao longo da História da Matemática. Outro exemplo foi na criação de uma das Geometrias Não-Euclidianas, a Hiperbólica.

Atualmente, Geometria Analítica tem pouca similaridade com as contribuições oriundas da sua criação por Fermat e Descartes. Uma marca mais atual deste fato corresponde ao uso de um par de eixos ortogonais, o que não era utilizado por nenhum dos dois. Nenhum desses criadores teve a ideia de centrar suas descobertas na utilização de equações para identificar curvas e superfícies. Coube a Fermat chegar à essa ideia, enquanto que Descartes voltou-se para a notação algébrica. 
Na dissertação, da qual é feito este recorte, foi adotado o sistema de coordenadas cartesianas, o qual consiste num par de eixos perpendiculares e orientados denotados por $\mathrm{OX}$ e OU, contidos num plano e com a mesma origem $\mathrm{O}$. Recorreu-se às coordenadas cartesianas com o intuito de resolver problemas de Geometria, unindo os fatos iniciais da Geometria Analítica aos resultados básicos da Geometria Euclidiana. No entanto, este não é o único método, por exemplo, existe o de coordenadas polares.

No que diz respeito à Investigação Matemática, como metodologia de ensino, Ponte et al. (2005) afirmam que "Para os matemáticos profissionais, investigar é descobrir relações entre objetos conhecidos ou desconhecidos, procurando identificar as respectivas propriedades" (p. 13). Isso vai ao encontro do indicado por Lakatos (1978), de ser uma ciência rigorosa como a formulada por Euclides, mas também de aparecer como experimental. Isso é reiterado por Polya (1887-1985), além de Bento de Jesus Caraça (PONTE et al., 2005).

A Investigação Matemática, geralmente, é realizada em torno de um ou mais problemas. Portanto, "o conceito de investigação matemática, como atividade de ensinoaprendizagem, ajuda a trazer à sala de aula o espírito da atividade matemática genuína, constituindo, por isso, uma poderosa metáfora educativa" (PONTE et al., 2005, p. 23). Nessa direção o autor informa que o aluno vai ser chamado para "agir como um matemático, não só na formulação de questões e conjecturas e na realização de provas e refutações, mas também na apresentação de resultados e na discussão e argumentação com os seus colegas e professores" (p. 23).

Por tais apontamentos, a proposta de realizar uma investigação, adaptada do clássico problema apresentado na presente pesquisa, a saber. "A Caça ao Tesouro", tem a ver com tais propósitos sugeridos pelo autor dessa metodologia, pois foram aplicadas as três fases indicadas: (a) introdução da tarefa, em que o professor faz a proposta à turma., oralmente ou por escrito; (b) realização da investigação, individualmente ou em grupos ou com toda a turma; (c) discussão dos resultados, em que os alunos relatam aos colegas o trabalho realizado (PONTE et al., 2005). Assim, justifica-se o recorte que se apresenta no presente artigo. 


\section{ENSIN@UFMS 2021}

ISSN 2525-7056

\section{Procedimentos metodológicos}

A pesquisa realizada tem abordagem qualitativa no sentido apontado por Severino (2016, p. 125): "[...] referir-se a conjuntos de metodologias, envolvendo, eventualmente, diversas referências epistemológicas". É participante, pois o "pesquisador coloca-se numa postura de identificação com os pesquisados" (Idem, p.126), uma vez que o primeiro autor é o professor dos sujeitos investigados e passou a interagir com os mesmos acompanhando e realizando a atividade em todos os momentos da investigação.

A coleta de dados foi abrangente, incluindo as conversações entre o pesquisador e os sujeitos da pesquisa, registros das considerações do professor e imagens capturadas. Segundo Myers (2017, p. 279), não existe uma listagem que das características relevantes para a análise de conversação a ser feita a partir da coleta de dados, ou seja, vai desde um "'oh' até risos, para avaliações de conclusões". Essa é importante na medida em que o pesquisador vai desde o que os sujeitos decidem sobre quem vai falar e como os grupos se relacionam com os que já falaram. Por sua vez, os participantes buscam decisão de qual tópico irão falar, especialmente no que for mais concreto. O pesquisador utilizou seu diário de bordo para o registro das conversações que desenvolvia com os estudantes durante a realização. Também, para esclarecer algumas dúvidas, posteriormente, em aulas subsequentes, voltou a indagá-los. Além disso, em uma segunda etapa, os mesmos puderam registrar a solução no software Geogebra, proporcionando ao professor outros olhares (o que não é registrado neste trabalho, por limitações, como explicitado).

\section{O cenário da pesquisa}

Quanto ao cenário da presente pesquisa, ela foi realizada com um grupo de 10 estudantes do ensino médio, participantes de um Clube de Matemática em uma escola privada da região central do Rio Grande do Sul, a qual tem filosofia marista. Esses serão denotados por Aluno 1, Aluno 2, ..., Aluno 10, a fim de evitar identificações. O primeiro autor é o professor desses alunos e tem por metodologia em suas aulas realizar atividades extraclasse de modo a estimulá-los a desenvolver atividades criativas que possam ilustrar os conteúdos envolvidos no referido nível de escolaridade, em conexão com a filosofia marista que orienta este espaço educacional. Há representação dos três anos no grupo e, quando o professor vai desenvolver um conteúdo que esteja envolvido em uma dessas atividades, os que participaram do projeto relacionado auxiliam o professor como monitores. 
Dessa forma, foi proposta uma atividade adaptada do problema já especificado. Preliminarmente, foi distribuído um texto envolvendo os aspectos históricos relativos ao tema para uma leitura em casa. Em função da principal característica da filosofia marista ser a simplicidade, o tesouro consistiu em localizar, simbolicamente, as vestimentas antigas utilizadas pelos religiosos. Ao final, foi realizada uma atividade recreativa para reativar a mística do hábito utilizado por eles.

Como nem todos conheciam o software GeoGebra, que seria utilizado, o professor fez uma atividade exploratória no laboratório de informática da escola para familiarizar a todos com as ferramentas disponível no aplicativo, o que não fará parte deste recorte feito da dissertação, ficando para um próximo artigo.

O problema original

A primeira referência ao problema foi encontrada em Barbeau (1989), cuja adaptação segue traduzida:

Um tesouro foi enterrado em uma ilha e foi feito um mapa de sua localização. As instruções contidas no mapa dizem que, ao desembarcar na ilha, avistam-se imediatamente dois grandes carvalhos e uma palmeira, conforme ilustrado na Figura 2.

Figura 2. Representação do Mapa do Tesouro

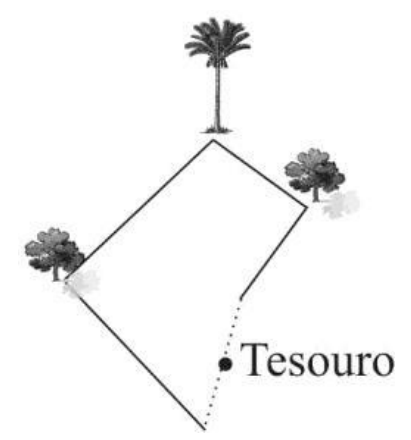

Fonte: Os autores.

O tesouro está enterrado em um ponto que pode ser encontrado da forma escrita a partir da sequência:

1. Partindo da palmeira, caminha-se até o carvalho A (Figura 3) contando os passos. 
Figura 3. Mapa sistematizado

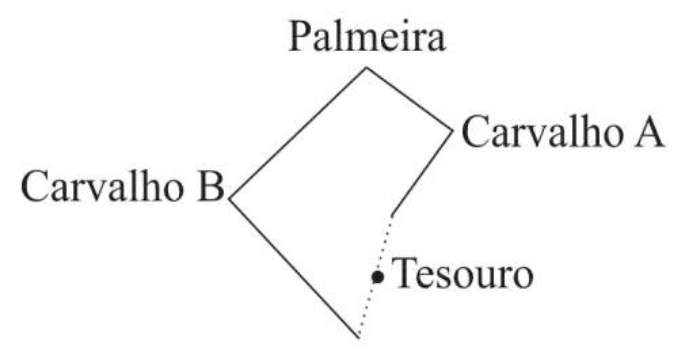

Fonte: Os autores.

2. Chegando ao carvalho, deve-se girar para a direita $90^{\circ}$ e caminhar o mesmo número de passos e, onde chegar, deve-se fazer uma marca.

3. Voltando novamente à palmeira, caminha-se até o carvalho B contando os passos; gira-se à esquerda $90^{\circ}$ e caminha-se o mesmo número de passos, fazendo-se uma marca nesta posição.

4. O tesouro está enterrado exatamente na reta que liga as duas marcas e à mesma distância das duas.

Consta que, em Barbeau (1989), depois de muito tempo, exploradores encontraram o mapa e decidiram ir à ilha resgatar o tesouro. Ao chegarem, tiveram uma desagradável surpresa. Os carvalhos ainda estavam lá, mas a palmeira havia desaparecido. Os exploradores não desanimaram e, depois de pensar um pouco, tiveram uma ótima ideia para resolver o problema de modo bastante prático, o que, no entender dos autores do artigo constitui um problema de Investigação Matemática relevante a ser explorado no ensino médio a fim de resgatar, inicialmente, a questão axiomática da Geometria Euclidiana, bem como um indicativo para incentivá-los para o processo dedutivo na Geometria.

Com a finalidade de estimular os participantes para a tarefa, foi repassada a história e assim responderem: como os exploradores fizeram para encontrar o lugar onde o tesouro estava enterrado e recuperá-lo mesmo sem a palmeira?

Como a escola havia completado 110 anos em 2013, muitas atividades alusivas foram realizadas desde o ano anterior, quando, ao final deste ano foi o lançamento de um livro comemorativo. O mesmo apresentava a história do colégio e ressaltava sua importância para a comunidade em que está inserida. Para relacionar o aniversário da 


\section{ENSIN@UFMS 2021}

ISSN 2525-7056

instituição, o lançamento do livro, os ideais do colégio e a Matemática, foi proposta a seguinte adaptação ao problema original.

Quando os primeiros irmãos maristas chegaram à cidade, um tesouro foi enterrado no campo de futebol do Parque São Luiz. Os irmãos confeccionaram um mapa de sua localização, o qual foi encontrado durante as pesquisas realizadas para a produção do livro comemorativo ao $110^{\circ}$ aniversário da escola.

No mapa estão as instruções com a localização do tesouro, as quais indicam que, ao chegar ao campo de futebol, se avista imediatamente as duas goleiras e uma palmeira. O tesouro está enterrado em um ponto que pode ser encontrado da forma descrita abaixo:

"Partindo da palmeira, caminhe até a primeira trave da goleira a sua esquerda, contando os passos. Chegando lá, gire para a direita $90^{\circ}$ e caminhe o mesmo número de passos. Onde chegar, faça uma marca. Voltando novamente à palmeira, ande até a primeira trave da goleira à sua direita contando os passos. Chegando lá, gire à esquerda $90^{\circ}$ e caminhe o mesmo número de passos, fazendo uma marca nesta posição. O tesouro está enterrado exatamente na reta que liga as duas marcas e à mesma distância das duas" (problema adaptado).

O objetivo da pesquisa

Para cumprir com tal objetivo, foram definidas atividades com os seguintes objetivos específicos:

- elaborar estratégia para determinar pontos no plano a partir de certos indicativos: árvore, goleira 1 , goleira 2 e tesouro;

- analisar se a localização do ponto de partida para a busca ao tesouro não interfere na solução matemática.

Na sequência do artigo são apresentados os detalhamentos de cada parte do recorte da pesquisa, constante do presente artigo, por atividade realizada e a respectiva análise.

\section{Discussão e Resultados}

É fato que alguns imprevistos surgem no cotidiano de uma sala de aula, e isso não deixou de ocorrer. A primeira atividade estava prevista para a tarde do dia 6 de maio, aproveitando para comemorar a passagem do Dia Nacional da Matemática. Devido ao mau tempo, a atividade precisou ser adiada. Diante da impossibilidade de ser realizada a saída, recorreu-se ao laboratório de informática, o que acabou não atrapalhando o andamento do 


\section{ENSIN@UFMS 2021}

ISSN 2525-7056

trabalho e tornou-se útil para a sequência do mesmo. Essa deveria ter sido a segunda atividade da pesquisa.

Atividade 1 - Primeiro contato com o GeoGebra

Antecipou-se a ida do grupo ao laboratório de informática e, assim, foi feita a introdução ao GeoGebra. Os estudantes tiveram um período de aula para manipularem o software livremente. Em seguida, foi distribuído um material impresso com orientações sobre o uso de algumas ferramentas do programa. Os estudantes tiveram um primeiro contato com o GeoGebra e, ao final do encontro, foi explicado que a atividade exigiria o uso desse programa sendo solicitado que instalassem o aplicativo em seus computadores pessoais para estudos complementares.

Esta etapa mostrou a facilidade com a qual os estudantes iniciaram os trabalhos com o GeoGebra. Isso é mais um indicativo de que o software é uma ferramenta viável para o ensino da Matemática no ensino médio. Na Figura 4 ilustra-se o laboratório de informática do colégio e a turma com a qual o trabalho foi aplicado.

Figura 4. Primeiro contato com o aplicativo

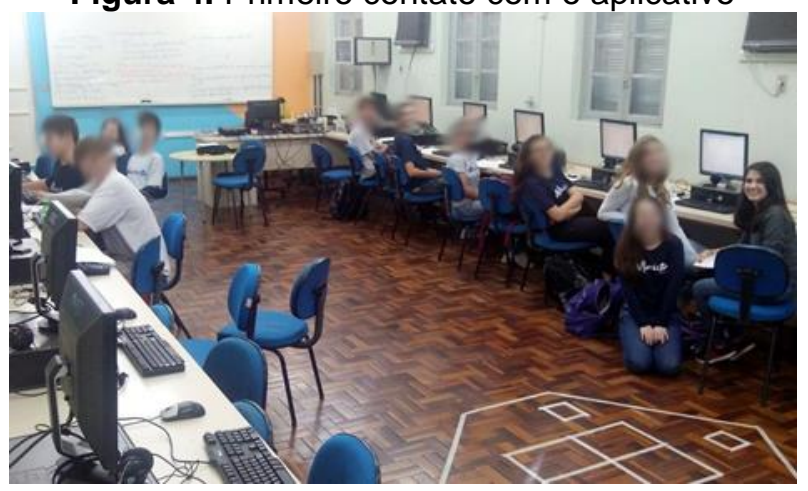

Fonte: Dados da pesquisa.

Assim, o objetivo da atividade foi alcançado uma vez que os alunos passaram a utilizar de forma plenamente satisfatória o software.

Atividade 2 - elaborando estratégias de solução

O objetivo dessa atividade foi obter uma estratégia para determinar um ponto específico no plano, atendendo certas orientações fornecidas, como indicado na Figura 5. 


\section{ENSIN@UFMS 2021}

ISSN 2525-7056

Figura 5. Sistematização proposta (Foto: Google)

Fonte: Dados da pesquisa.

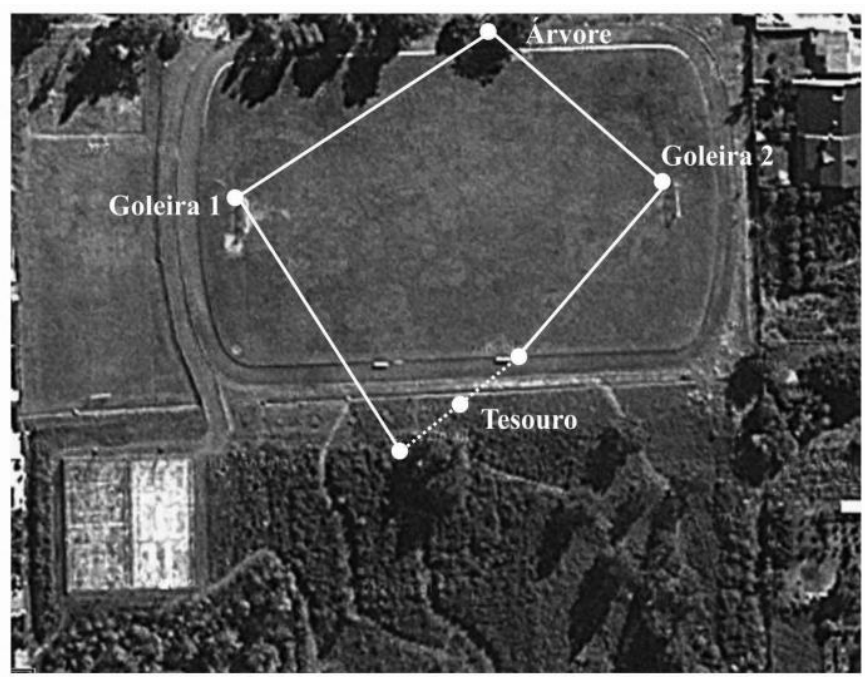

Na Figura 5 ilustra-se um esquema ao qual os estudantes seriam desafiados a criarem outro semelhante, explorando ferramentas do Geogebra adquiridas na atividade 1. Para sua realização, os participantes se organizaram em grupos e escolheram uma estratégia para localizar o ponto indicado no problema adaptado, ou seja, um ponto de referência desconhecido. Nessa atividade foram envolvidos os seguintes conteúdos: ponto médio; distância entre dois pontos; perpendicularidade; rotação. Com isso, os estudantes exploraram o senso de localização e locomoção de forma intuitiva. Isso corrobora com os pressupostos da Investigação Matemática, como metodologia de ensino e de aprendizagem e vai ao encontro do conteúdo de Geometria Analítica.

A atividade teve a duração de três aulas (150 minutos) e, para sua execução, foi fornecido: cópia impressa das orientações, incluindo o Mapa do Tesouro; transporte da turma até o Parque São Luís, onde seria realizada a atividade.

Durante o percurso, os estudantes se organizaram em grupos (dois com três e um com quatro), estudaram o material fornecido, discutiram entre eles e elaboraram suas estratégias, o que vai ao encontro do que afirma Ponte et al. (2005, p. 23) "agir como um matemático, não só na formulação de questões e conjecturas [...], mas também na discussão e argumentação com os seus colegas e professores" (p. 23). No caso, entre eles, uma vez que o professor os deixou à vontade, sem interferir. Na Figura 6, constam os dados que nortearam os estudantes. 
Figura 6. Instruções para a caça ao tesouro

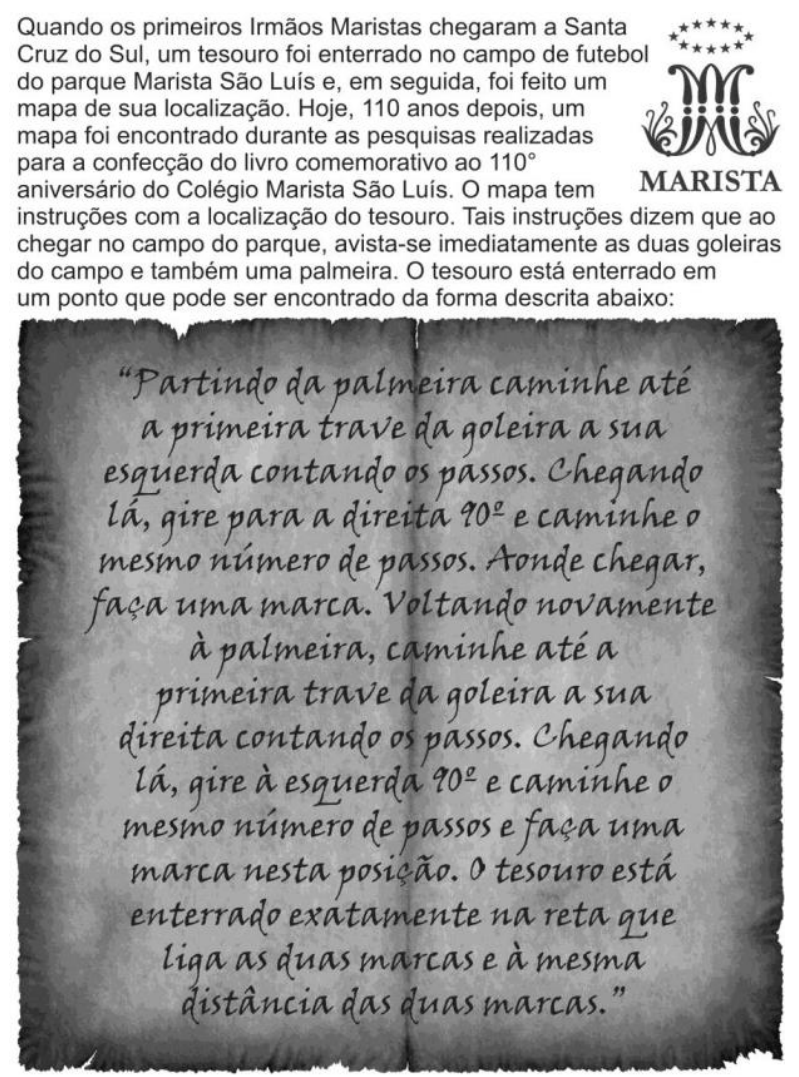

Fonte: Dados da pesquisa.

Como era necessária a descoberta por equipes, um dos grupos fazia a busca e os outros ficaram aguardando seu retorno na sede social. Para aumentar a motivação e agilização, cada grupo teve até 20 minutos para encontrar o tesouro.

O professor acompanhava cada grupo durante a busca e questionava sobre a existência da palmeira (ponto inicial da procura), fazendo com que os estudantes percebessem que não existe mais tal referência e persuadia o grupo a escolher um ponto de partida qualquer. Para a atividade fornecer mais subsídios para a discussão final, ele induzia os grupos a iniciarem a busca pelo tesouro a partir de pontos de referência diferentes.

Depois que todos os grupos terminaram a sua caça ao tesouro, um representante de cada trio (ou quarteto) explicou para o restante da turma qual foi a estratégia utilizada para achar o local onde o tesouro estava enterrado. Enquanto os estudantes teciam explicações, o professor destacava o ponto inicial que cada grupo havia escolhido. Ele dava ênfase, nesse momento da atividade, ao fato de o tesouro não ter sido trocado de lugar durante a busca. Essa intenção era de que os estudantes percebessem que, mesmo desconhecendo 


\section{ENSIN@UFMS 2021}

ISSN 2525-7056

o ponto inicial, era possível encontrar a raridade escondida. Concluindo a atividade, cada grupo deveria, posteriormente, comparar sua solução com as apresentadas pelos demais grupos.

Durante todo o desenrolar da atividade, o professor fomentou discussões matemáticas, incentivou a troca de ideias, valorizou as "ideias erradas", sempre tentando mostrar aos grupos onde estaria o erro e como corrigi-lo. Enfim, considera-se que o docente deve atuar fortemente no sentido de conduzir os grupos e garantir que os estudantes atinjam o objetivo. Ainda, não é suficiente apenas encontrar o tesouro, mas pensar e conjecturar acerca do problema.

A importância de fazer os registros, tanto por parte do professor quanto por parte dos estudantes é um fator importante de ser levado em consideração a fim de não perder os fatos a serem levados à discussão posteriormente. Portanto, os grupos devem anotar o ponto de partida, o número de passos que deram até cada goleira e o número de passos das marcas até o tesouro. Embora a atividade tenha transcorrido de forma tranquila e produtiva, algumas dificuldades surgiram, sendo a primeira delas a identificação da palmeira, a qual era o ponto inicial para dar início à busca do tesouro (Figura 7).

Figura 7. A dificuldade em identificar a palmeira

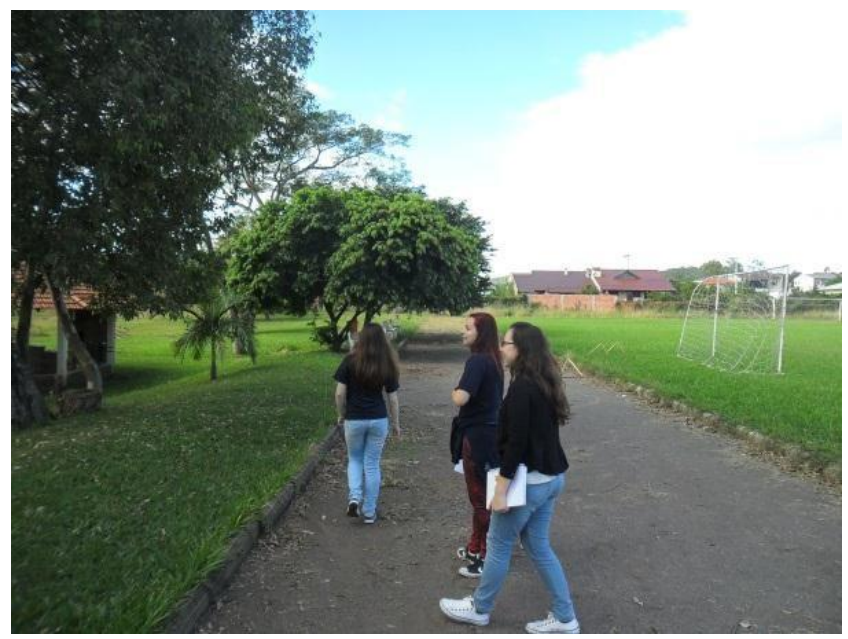

Fonte: Dados da pesquisa

Alguns grupos procuraram uma palmeira grande, enquanto outros, uma palmeira mais antiga, dois critérios distintos a serem observados. Um dos grupos percebeu um tronco de árvore cortado e, como era uma árvore aparentemente mais antiga, este grupo escolheu aquele para ser o ponto de partida do grupo (Figura 8). 


\section{ENSIN@UFMS 2021}

ISSN 2525-7056

Figura 8. Tronco cortado ao ponto inicial

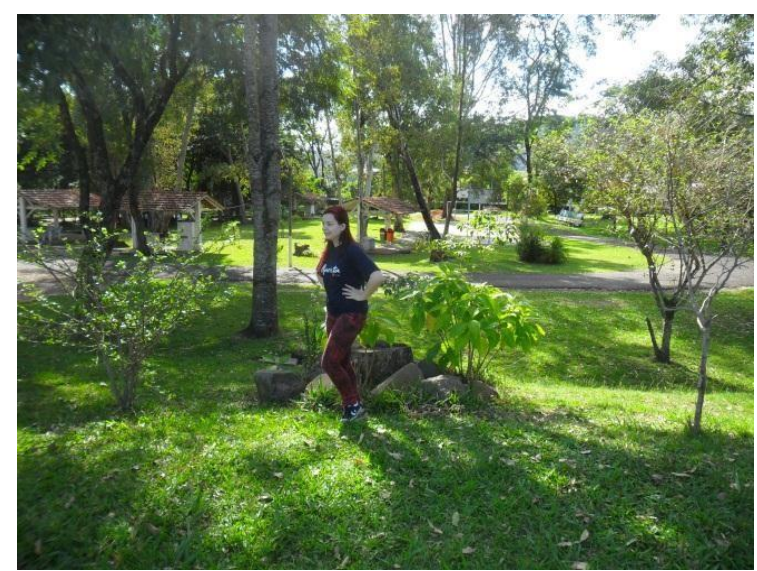

Fonte: Dados da pesquisa.

Alguns grupos se subdividiram para que as chances de encontrarem o rumo certo aumentassem. Depois de discutirem sobre qual ponto inicial deveriam tomar, decidiram escolher três pontos de partida diferentes. O professor permitiu a mudança na regra para despertar a curiosidade sobre o fato de todos chegarem ao mesmo local.

A caça ao tesouro foi feita de forma independente pelos grupos, sendo que um não acompanhava os outros. Foram anotados os nomes dos integrantes para marcar o local final que cada trio chegou, seguindo as instruções recebidas do professor.

Quando todos os grupos terminaram a caçada, os estudantes foram para o campo e ficaram no ponto ao qual haviam determinado para ser o local do tesouro escondido. Diferentemente do esperado, nem todos ficaram na mesma posição. Apenas dois estudantes de um dos grupos que se subdividiu encontraram o mesmo lugar. Todos os demais grupos acharam locais diferentes, porém com pequena divergência de distância entre eles (Figura 9).

Figura 9. Tronco cortado ao ponto inicial

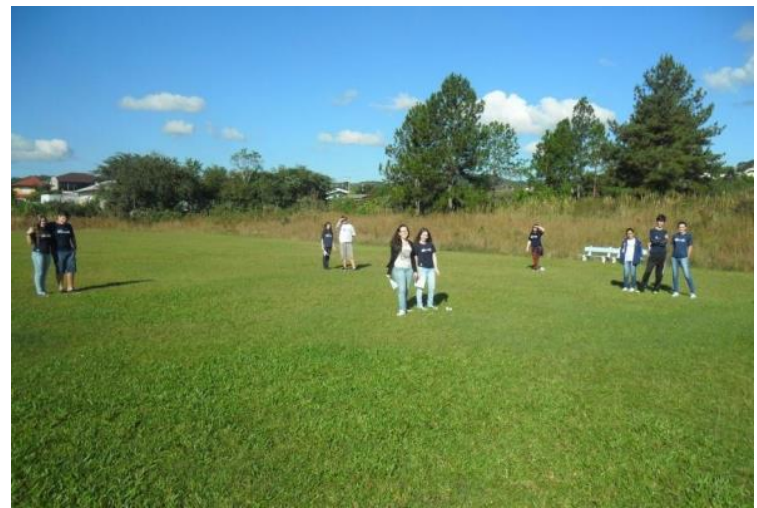

Fonte: Dados da pesquisa. 
Durante a discussão final, os estudantes localizaram o mesmo ponto final, lideraram a discussão na tentativa de convencer os demais colegas de que o ponto inicial era indiferente. Neste momento, a intervenção do professor se fez presente para informar que, de fato, não importava o ponto escolhido para iniciar a busca. Acataram a explicação passando a discussão sobre o porquê ter ocorrido desencontro entre os destinos de cada trio. Desejaram conhecer quais os motivos os levaram a lugares diferentes, ao mesmo tempo em que elencaram algumas possíveis causas para o desencontro, como as que seguem:

- dificuldade de andar em linha reta;

- o fato de um trio ter escolhido uma palmeira que ficava abaixo do nível do campo (portanto, precisou percorrer uma subida até chegar à trave) e isso deu diferença no número de passos dados após a rotação de $90^{\circ}$;

- dificuldade de determinar o ângulo de 90ㅜ;

- o fato de um estudante ter contado os passos até a goleira da direita e outro estudante ter contado os passos até a goleira da esquerda;

No momento em que o professor disse que o ponto de partida não iria interferir na chegada ao destino correto, todos ficaram convencidos. No entanto, apresentaram outros questionamentos sem deixar de aceitar a explicação do professor, mesmo sem ele ter usado prova matemática do fato. No momento da discussão, o professor foi bastante enfático ao dizer que eles não poderiam ter se convencido com tanta facilidade. Chama-se atenção para o fato de que, na Matemática, se precisa provar os fatos e não apenas acreditar neles. Destaca-se aqui a importância fundamental de explorar 'provas' para que o ponto inicial seja indiferente e não influenciar na descoberta do ponto final, sendo esse um dos objetivos da próxima atividade.

Atividade 3 - transportando ao Geogebra as soluções

O objetivo dessa atividade foi obter, pelo uso do aplicativo GeoGebra, uma representação visual da situação vivenciada na Atividade 2. Ao utilizar esse instrumento, um aplicativo dinâmico, os estudantes poderiam perceber que a árvore inicial não importaria para determinar o local onde se encontrava o tesouro.

$\mathrm{Na}$ atividade, são desenvolvidos os seguintes conteúdos: ponto médio e rotação. 
Para a realização da atividade, esperava-se que os estudantes tivessem adquirido as ferramentas do GeoGebra, exploradas na primeira parte do trabalho investigativo. Além disso, era esperado que eles tivessem domínio dos seguintes conteúdos, já desenvolvidos em anos anteriores e constante do currículo escolar: noções e proposições primitivas (ponto, reta, plano); segmento de reta; ângulos; perpendicularidade; domínio de ferramentas do GeoGebra.

A atividade teve a duração prevista de duas aulas (100 minutos) e foi realizada no laboratório de informática, com os estudantes ocupando as máquinas individualmente. Logo em seguida, solicitaram ao professor para sentarem juntos conforme o grupo que havia realizado a atividade a fim de acompanharem o material escrito e anotações. Foi concedido o que haviam solicitado, porém, todos deveriam realizar as atividades no seu computador e registrá-las para encaminhar ao professor. No entanto, alguns estudantes optaram por fazer individualmente, sem discussões ou trocas com o restante dos componentes de seu grupo.

Inicialmente, voltaram à primeira atividade. Foi retomado, pelo professor, o fato de que cada grupo partiu de uma dada árvore; que o tesouro não mudou de lugar bem como as goleiras; e que havia pontos móveis além dos fixos, dentre outros questionamentos.

Apesar das orientações e questionamentos emanados pelo professor e sua expectativa ser que utilizassem o fato do ponto inicial da caça ser indiferente, na prática isso não ocorreu, como é próprio de uma atividade investigativa em que as soluções, muitas vezes, são criativas e fogem ao que o investigador esperava. Entretanto, aspectos relevantes para as conclusões foram expostos, como por exemplo, "devemos começar a atividade marcando o tesouro no GeoGebra?" (Aluno 1)4; "podemos colocar o ponto inicial na origem?" (Aluno 2); "podemos colocar o tesouro na origem?" (Aluno 3).

As manifestações desses estudantes mostravam que eles estavam conseguindo relacionar a situação real com uma representação no GeoGebra (Figura 10).

\footnotetext{
${ }^{4}$ A fim de não identificar os estudantes, os designamos por numerais.
} 


\section{ENSIN@UFMS 2021}

Figura 10. Tronco cortado como ponto inicial

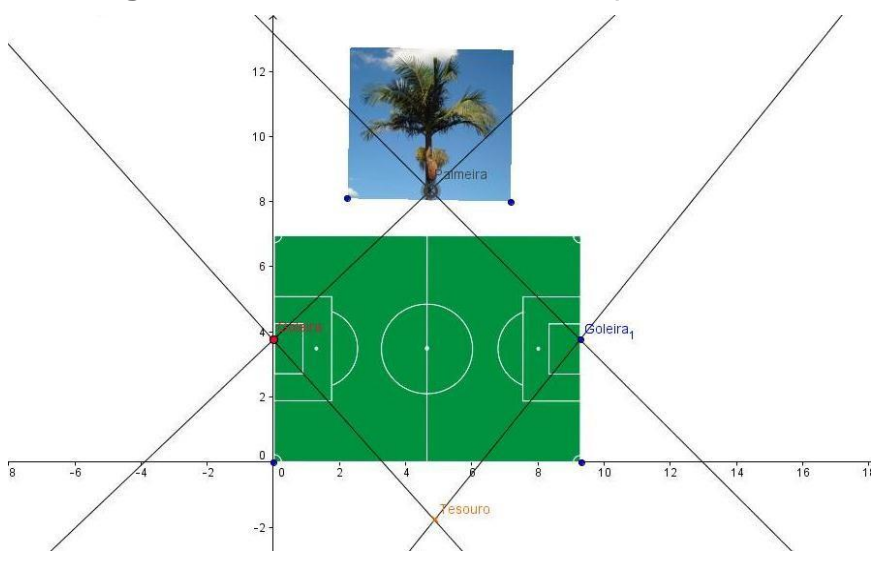

Fonte: Dados da pesquisa.

Entende-se que o objetivo da atividade foi atingido, uma vez que os discentes conseguiram retratar, no aplicativo, a situação vivenciada, repassando ao professor as respectivas soluções.

Por limitação de espaço para o artigo e pelas inúmeras explorações realizadas pelos estudantes, as soluções e respectivas análises constituirão um segundo artigo, no qual os detalhes da exploração no GeoGebra serão feitos.

\section{Considerações Finais}

Neste artigo apresenta-se um recorte de uma dissertação de mestrado, que utilizou a Investigação Matemática como metodologia de ensino para resolver um problema adaptado do clássico "Caça ao tesouro" para o ensino médio. Embora a solução do problema original seja conhecida, a adaptação do mesmo exigiu novas estratégias para encontrar a solução. Envolveu um grupo de estudos motivacionais, elaborado pelo primeiro autor e professor das três turmas que se envolveram nas atividades. O grupo é de participação livre e, no presente trabalho, envolveu 10 participantes com estudantes dos três anos.

Entendeu-se que o objetivo geral de analisar como estudantes do ensino médio realizam uma atividade investigativa na resolução de uma adaptação do problema 'A Caça ao Tesouro', foi plenamente alcançado. Todos eles se envolveram nas atividades, desde a compreensão do problema e o delineamento de estratégias para a sua realização, como é recomendado na própria metodologia empregada. Foi notável a empolgação dos estudantes, mesmo durante o deslocamento da escola para o local do evento, um parque 
da própria instituição, mas deslocado da sede, o que exigiu um transporte. No deslocamento havia uma disputa eloquente entre os grupos formados a respeito da intencionalidade de cada um, uma vez que já possuíam certo conhecimento do local.

No início, houve necessidade de alteração/adaptação do plano na sequência das atividades, uma vez que iniciaram, então, pelo reconhecimento, em laboratório, sobre ferramentas do software, o que utilizado após a 'caça ao tesouro'.

A análise constante do presente artigo indicou apenas o primeiro movimento exploratório na representação no referido software das soluções encontradas pelos grupos formados. Contudo, foi possível intuir que os conhecimentos, inicialmente adquiridos, sobre tal software foram suficientes para ilustrar como foi possível traduzirem suas estratégias de solução em uma representação dinâmica. Considerando os registros do pesquisador em seu diário de bordo, as conversações realizadas e as representações feitas pelos grupos, foi possível concluir que todos eles conseguiram esboçar os elementos que nortearam a obtenção do problema.

Como todos os grupos confrontaram suas estratégias com a solução do problema, in locus, entendeu-se que o objetivo geral da pesquisa foi alcançado de forma satisfatória. Além disso, a pesquisa mostrou que os fatos históricos trazidos pelo professor motivaram os estudantes a buscarem resolver o problema de forma criativa e com entusiasmo o que nem sempre ocorre em aulas convencionais. Dessa forma, a metodologia de ensino Investigação Matemática mostrou-se eficiente para os sujeitos envolvidos na pesquisa uma vez que as três fases indicadas por Ponte et al. (2005) foram observadas, isto é, (a) a introdução da tarefa foi feita por meio da apresentação de um texto histórico pelo professor e discutida oralmente com a turma; (b) a realização da investigação foi realizada por grupos, separadamente; (c) a discussão dos resultados ocorreu quando foi proporcionado aos grupos relatarem suas soluções ao mesmo tempo que promoviam representações das respectivas soluções no software GeoGebra.

\section{Referências}

BOYER, C.B. História da Matemática. São Paulo: Edgard Blucher, 2010.

BARBEAU, E.J. Polynomials. Springer-Verlag, 1989.

BRASIL. Ministério da Educação. Base Nacional Comum Curricular. Brasília, 2017. 
EVES, H. Introdução à história da matemática. Campinas, SP: Editora da UNICAMP, 2004.

LAKATOS, I. A Lógica do Descobrimento Matemático - Provas e Refutações. (org. WORRAL, J. e ZAHAR, E.). Rio de Janeiro: Zahar, 1978.

MYERS, G. Análise da conversação e da fala. In: BAUER, M.W.; GASKELL, G. Pesquisa Qualitativa com texto, imagem e som: um manual prático. 13a. ed. Petrópolis : Vozes, 2. reimpressão 2017.

PONTE, J. P. da; BROCARDO, J.; OLIVEIRA, H. Investigações matemáticas na sala de aula. $1^{\text {a }}$ ed., Belo Horizonte: Autêntica, 2005.

RODRIGUES, G. R. Uma abordagem para o problema do Mapa do Tesouro aplicado ao ensino de Geometria. Dissertação de Mestrado (Programa de Pós-Graduação em Matemática em Rede Nacional - PROFMAT- UFSM), 2014, 64p.

REIS, I. Fundamentos da Matemática. Editora Moderna, 1996.

ROQUE, T; CARVALHO, J.B.P. Tópicos de história da Matemática. Rio de Janeiro: SBM 2012.

SEVERINO, A.J. Metodologia do trabalho científico. 24. ed. Revista e atualizada. São Paulo: Cortez, 2016.

\section{NOTAS}

\section{IDENTIFICAÇÃO DO TEXTO}

O presente texto é uma adaptação de Uma Abordagem para o Problema do Mapa do Tesouro Aplicado ao Ensino da Geometria no Ensino Médio, dissertação de Mestrado Profissional em Matemática em Rede Nacional (Profmat) apresentado na Universidade Federal de Santa Maria, em 29/08/2014, elaborada sob orientação da Professora Dra. Lidiane Buligon0 e co-orientação da professora Dra. Carmen Vieira Mathias.

\section{IDENTIFICAÇÃO DE AUTORIA}

Gustavo Rosas Rodrigues. Professor do Ensino Básico. Mestre pelo Programa de Mestrado Profissional em Matemática em Rede Nacional (Profmat), Universidade Federal de Santa Maria (UFSM), Santa Maria, RS, Brasil.

E-mail: gus_santacruz@yahoo.com.br

(iD) https://orcid.org/0000-0003-0172-8389

José Carlos Pinto Leivas. Doutor em Educação pela Universidade Federal do Paraná. Professor do Programa de Pós-Graduação em Ensino de Ciências e Matemática da Universidade Franciscana (UFN); líder do Grupo de Estudos e Pesquisas em Geometria (GEPGEO), Santa Maria, RS, Brasil.

E-mail: leivasjc@gmail.com

(D) https://orcid.org/0000-0001-6876-1461

Lidiane Buligon. Doutora em Física pela Universidade Federal de Santa Maria. Docente no Mestrado Profissional em Matemática em Rede Nacional (Profmat), Universidade Federal de Santa Maria (UFSM), Santa Maria, RS, Brasil. 
E-mail: profbuligon@gmail.com

(1) https://orcid.org/0000-0002-5907-3584

\section{AGRADECIMENTOS}

Não se aplica.

\section{FINANCIAMENTO}

Não se aplica.

\section{CONSENTIMENTO DE USO DE IMAGEM}

Não se aplica.

\section{APROVAÇÃO DE COMITÊ DE ÉTICA EM PESQUISA}

Não se aplica.

\section{LICENÇA DE USO}

Autores mantêm os direitos autorais e concedem à revista ENSIN@ UFMS - ISSN 2525-7056 o direito de primeira publicação, com o trabalho simultaneamente licenciado sob a Licença Creative Commons Attribution (CC BY-NC-SA 4.0), que permite compartilhar e adaptar o trabalho, para fins não comerciais, reconhecendo a autoria do texto e publicação inicial neste periódico, desde que adotem a mesma licença, compartilhar igual.

\section{EDITORES}

Patricia Helena Mirandola Garcia, Eugenia Brunilda Opazo Uribe, Gerson dos Santos Farias.

\section{HISTÓRICO}

Recebido em: 15/09/2021 - Aprovado em: 21/11/2021 - Publicado em: 15/12/2021.

\section{COMO CITAR}

RODRIGUES, G. R; LEIVAS, J. C. P; BULIGON, L. Investigação com o Problema do Mapa do Tesouro. Revista ENSIN@ UFMS, Três Lagoas, v. 2, número especial, p. 143-163. 2021. 